[Review]

\title{
可释放一氧化氮纳米材料的研究进展
}

\author{
向慧静 1,2 刘劲刚 ${ }^{2, *}$ 赵彦利 ${ }^{1, *}$ \\ ( ${ }^{1}$ 南洋理工大学数理科学学院化学与化学生物系, 新加坡 637371 ; \\ 华东理工大学化学与分子工程学院, 先进材料教育部重点实验室, 上海 200237)
}

\begin{abstract}
摘要: 一氧化氮(NO)是一种内源性双原子分子, 在许多生理学和病理学过程中起了关键的调节作用, 包括血 管平滑肌松驰、免疫反应、神经传递、呼吸作用、细胞调亡等。 NO 的生理调节作用在很大程度上依赖于 NO 释放的位置、时间以及剂量。开发出能够储存 NO 并且在指定的地点和时间释放需求量的 NO 的纳米运输平 台是非常重要的研究课题。此篇综述, 主要介绍近期我们课题组和其他研究人员在 NO控制释放以及生物学 应用的研究进展。本文首先概述了几类具有应用前景的外源性 NO供体, 如偶氮二醇烯、亚硝基硫醇、硝基 苯和金属亚硝酰化合物。然后, 重点讨论了结合 NO 供体和纳米平台在控制释放 NO和生物医学的潜在应用。
\end{abstract}

关键词: 控制释放; 纳米医学; 一氧化氮; NO运输平台; NO供体

中图分类号: 0647

\section{Recent Research Advancements in NO-Releasing Nanomaterials}

\author{
XIANG Hui-Jing ${ }^{1,2} \quad$ LIU Jin-Gang ${ }^{2, *} \quad$ ZHAO Yanli ${ }^{1, *}$ \\ ('Division of Chemistry and Biological Chemistry, School of Physical and Mathematical Sciences, Nanyang Technological \\ University, 21 Nanyang Link, Singapore 637371; ${ }^{2}$ Key Laboratory for Advanced Materials of MOE, School of Chemistry and \\ Molecular Engineering, East China University of Science and Technology, Shanghai, 200237, P. R. China)
}

\begin{abstract}
Nitric oxide (NO) - an endogenous diatomic molecule - plays key roles in various physiological and pathological processes, including smooth muscle relaxation in blood vessels, immune response, neurotransmission, respiration, and cell apoptosis. The biological functions of this molecule greatly depend on the location, timing, and dosage at which it is released. It is important to develop NO-delivery platforms capable of holding NO stably during storage and subsequently release optimal amounts of NO spatiotemporally at the desired location and time. In this review, recent advancements in the preparation of new exogenous NO donors including diazeniumdiolates, $S$-nitrosothiols, nitrobenzene, and metal-nitrosyl complexes are discussed. The integration of these NO donors with various nanoplatforms for controlled NO delivery and their potential applications in the biomedical field are highlighted.
\end{abstract}

Key Words: Controlled release; Nanomedicine; Nitric oxide; Nitric oxide delivery nanoplatform; Nitric oxide donor

1 引言

多年以前, 一氧化氮 $(\mathrm{NO})$ 被人们认为是一种
环境污染物而无调节生理过程的作用。直至 1980

年, Ignarro 发现了 NO 可作为内皮衍生的舒张因子

Received: December 1, 2016; Revised: February 3, 2017; Published online: February 9, 2017.

*Corresponding authors. ZHAO Yanli, Email: zhaoyanli@ntu.edu.sg; Tel: +65-63168792.

LIU Jin-Gang, Email: liujingang@ecust.edu.cn; Tel: +86-21-64252773

The project was supported by the Singapore Academic Research Fund (RG112/15), NTU-Northwestern Institute for Nanomedicine, and National

Natural Science Foundation of China (21571062).

新加坡学术研究基金(RG112/15), 南洋理工大学-西北大学纳米医学联合研究所及中国国家自然科学基金(21571062)资助项目

(c) Editorial office of Acta Physico-Chimica Sinica 
$(E D R F)^{1}$ 。这个独特的生理调节作用, 引起了科学 家们的广泛关注 ${ }^{2}$ 。如今, 越来越多的研究发现 NO 在很多其他的生理过程中起了重要作用, 如血压 调节、免疫反应、神经传递、癌细胞死亡等 ${ }^{3-5}$ 。 内源性 NO 主要来源于 L-精氨酸, 有三种同功酶可 将 $\mathrm{L}$-精氨酸转化为 $\mathrm{L}-$ 瓜氨酸和 $\mathrm{NO}^{6-9}$, 它们分别 是: (A) 神经元 $\mathrm{NO}$ 合成酶(nNOS), 主要存在于神 经元细胞和骨骼肌中; (B) 内皮细胞 NO 合成酶 (eNOS), 主要存在于内皮细胞和上皮细胞, 有时 也存在于某些神经元细胞中; (C) 可诱导 NO 合成 酶(iNOS), 广泛分布于人体, 特别是在巨噬细胞、 肝细胞、星形胶质细胞和平滑肌细胞中。另外, 在生物体中分布有大量的有机氮化合物能够产生 $\mathrm{NO}$, 如硝酸酯、亚硝酸酯、亚硝基硫醇以及过渡 金属的 $\mathrm{NO}$ 供体 ${ }^{6-9}$ 。

由于 $\mathrm{NO}$ 是气体分子, 在体内半衰期比较短, 容易与很多原子和自由基发生化学反应。如 $\mathrm{NO}$ 与 $\mathrm{O}_{2}$ 生成 $\mathrm{NO}_{2}$, 与超氧根离子反应生成对细胞有毒的 过氧亚硝酸盐。除此之外, NO还可以与氧合血红

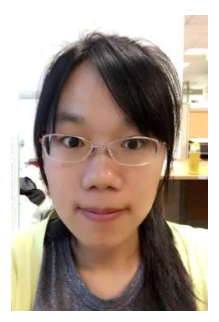

向慧静, 2013 年 9 月至今为华东理工 大学化学与分子工程学院无机化学 专业非定向博士研究生, 于 2015 年 12 月公派联合培养到新加坡南洋理 工大学数理科学学院化学与生物化 学系赵彦利课题组进行为期两年的 研究学习, 主要研究方向为无机纳米载体在药物 运输中的应用。
蛋白反应生成高铁血红蛋白和亚硝酸盐 ${ }^{10}$ 。需要强 调的是, $\mathrm{NO}$ 在生物体中的生物作用依赖于 $\mathrm{NO}$ 的 浓度和细胞内外的微妙变化来完成的。在正常的 生理条件下, 机体产生少量的 NO用来调节血管扩 张、神经传递、抗炎反应和抗氧化反应等 ${ }^{11-17}$ 。然 而, 组织中高浓度的 NO 可以增强巨噬细胞对于肿 瘤细胞的毒性, 抑制肿瘤细胞的增殖, 并加速肿 瘤细胞的调亡。一方面, NO通过抑制线粒体呼吸 作用, 改变铁的代谢和与一些酶的相互作用来破 坏肿瘤细胞的生长。另一方面, $\mathrm{NO}$ 与氧自由基结 合, 生成一系列活性氧, 破坏肿瘤细胞中的蛋白 质和核酸而间接促进肿瘤细胞的死亡 ${ }^{11-21}$ 。 $\mathrm{NO}$ 在 生理调节过程的双刃剑作用, 吸引了广大研究人 员研究开发外源性 NO 供体, 能够在特定的位置和 时间释放定量的 $\mathrm{NO}$ 。本综述主要介绍近期在外源 性 NO 供体设计以及结合 NO 供体和当今的纳米技 术在生物领域的应用的研究进展。首先简单的介 绍具有存储和即时释放 NO 的几类代表性化合物, 即 $\mathrm{NO}$ 供体, 如偶氮二醇烯类、亚硝基硫醇类、硝 基苯类、金属亚硝酰化合物、有机硝酸酯和有机 亚硝酸酯。然后重点介绍 $\mathrm{NO}$ 供体和新型纳米材料 组装成的 NO 运输材料, 纳米载体包括有二氧化 硅、二氧化钛、上转化纳米粒子、碳材料和量子 点等。最后总结和展望了负载 $\mathrm{NO}$ 的材料在生物医 学领域的潜在应用。

\section{NO供体}

\section{1 偶氮二醇烯盐类(NONOates)}

偶氮二醇烯盐可以分为两大类, 碳键构建的

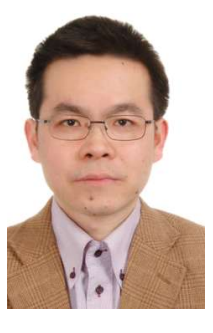

刘劲刚, 教授、博士生导师。2000 年 6 月获中山大学理学博士学位。 2000 年 7 月至 2001 年 6 月, 同济大学 化学系讲师。2001 年 8 月至 2003 年 8 月, 在日本九州大学基础有机化学研 究所任日本学术振兴会外国人特别研 究员。2003 年 9 月至 2011 年 8 月, 在日本九州大学 先导物质化学研究所先后任学术研究员、特任助 理教授和特任准教授。2011年9月任华东理工大学 校特聘教授。研究领域为生物无机化学, 主要进 行无机纳米药物的光控释放, 与能量转化相关的 仿生模拟与催化的研究。

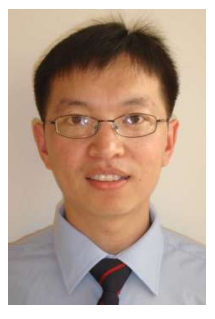

赵彦利, 南洋理工大学副教授。2000 年和 2005 年分别在南开大学获得本 科和博士学位, 后在美国加州大学洛 杉矶分校以及西北大学从事博士后研 究。主要从事新型超分子材料在纳米 医学和气体分离转化方面的研究。 
偶氮二醇烯盐和氮键构建的偶氮二醇烯盐, 在此 我们将重点讨论氮键构建的偶氮二醇烯盐 ${ }^{10,22,23}$ 。氮 键构建的偶氮二醇烯盐作为 $\mathrm{NO}$ 供体广泛应用于生 物体中。在生理条件下, 一分子的偶氮二醇烯盐 可以水解生成两分子的 $\mathrm{NO}$, 并且 $\mathrm{NO}$ 释放不需要 独特的代谢或者氧化还原反应, 因此此类 $\mathrm{NO}$ 供体 可以方便地应用于生物医学研究 ${ }^{10}$ 。

偶氮二醇烯盐类是由二级胺和亲电加成物在 高压 $\mathrm{NO}$ 条件下, 在甲醇和甲醇钠的存在下生成偶 氮二醇烯盐。偶氮二醇烯盐类释放 $\mathrm{NO}$ 的半衰期由 几秒到几周不等, 具体的 $\mathrm{NO}$ 释放动力学可由母体 结构来决定的, 例如母体分子大小, 取代基是环 状还是线性的脂肪胺, 或者由偶氮二醇烯与连接 在母体分子上的胺和羟基的分子内或分子间氢键 相互作用 ${ }^{23-26}$ 。除此之外, 还可以将偶氮二醇烯分 子上共轭连接酶或代谢物响应基团, 由特定的酶 或代谢物来调节和控制 NO 的释放速率(图 1)。

2012 年, Kelso 等 ${ }^{27}$ 报道了一种新的头孢菌素 取代的偶氮二醇烯衍生物 $\mathbf{1}$, 此化合物在内酰胺酶 活化下释放 NO, 在驱散 P. Aeruginosa 生物膜上有 潜在的应用。另外, 此 NO供体独特的优势在于 $\mathrm{NO}$ 供体只有接触生物膜表面的内酰胺酶才能释放 $\mathrm{NO}$, 有针对性地杀死生物膜部位感染的细菌, 同 时减少了 $\mathrm{NO}$ 带来的副作用。之后, Chakrapani
等 28,29 设计出芳基苯硼酸酯取代的偶氮二醇烯衍生 物 $2(\mathrm{BORO} / \mathrm{NO})$, 此衍生物在 $\mathrm{H}_{2} \mathrm{O}_{2}$ 的刺激下释放 $\mathrm{NO}$, 并且此 NO 供体可以穿透细菌的膜, 在细胞 内的活性氧(ROS) 的作用下释放 NO。Zhao 等 ${ }^{30}$ 在 2013 年报道了糖取代的偶氮二醇烯盐 5 自组装形成 水凝胶, 通过向水凝胶中加入糖苷酶会诱导 $\mathrm{NO}$ 的 释放。同时, 释放 NO 的浓度可由加入的糖苷酶的 浓度决定。此水凝胶释放微量的 NO 可促进伤口处 的血管增殖, 加速伤口愈合。

\section{2 亚硝基硫醇(RSNO)}

第二种被广泛应用的 NO 供体是亚硝基硫醇 (图 2)。亚硝基硫醇不仅可以储备 NO, 还可以在生 物体中运输 $\mathrm{NO}$ 。相比于其他 $\mathrm{NO}$ 供体, 亚硝基硫 醇的优势是具有良好的生物兼容性。在人体的血 液和组织中广泛分布天然存在的亚硝基硫醇, 如 谷胱甘肽硫醇, 白蛋白硫醇, 半胱氨酸硫醇等。 然而, 在生物体中, 亚硝基硫醇的形成机理尚不 明确。在实验室条件下, 亚硝基硫醇是由硫醇与 亚硝酸在强酸条件下反应生成。但是此种方法仅 适用于低分子量硫醇类化合物, 如谷胱甘肽。对 于高分子量的硫醇, 如蛋白, 主要通过转亚硝基 反应来实现, 将亚硝鎓离子从低分子量硫醇转移 到蛋白硫醇上 ${ }^{10,20,21,31}$ 。

与偶氮二醇烯盐类化合物相比, 亚硝基硫醇<smiles>CCN(CC)[N+]([O-])=NOCC1=C(C(=O)OC)N2C(=O)[C@H](NC(=O)Cc3ccccc3)[C@H]2SC1COCc1cn(C)c2c1C(=O)C(OC)CC2=O</smiles>

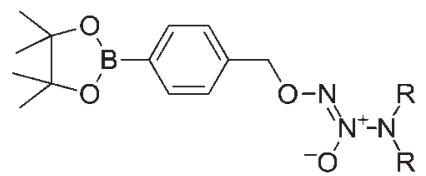

2<smiles>COC(=O)C1=C(CON=[N+]([O-])N(C)C)C(=O)c2ccccc2C1=O</smiles>

4<smiles>O=C(CNC(=O)CNC(=O)C(Cc1ccccc1)NC(=O)C(Cc1ccccc1)NC(=O)Cc1ccc2ccccc2c1)NCC(=O)NCc1cn(CCN2CCN([N+](=O)[O-])CC2)nn1</smiles>

图 1 一些偶氮二醇烯衍生物的化学结构式

Fig.1 Chemical structures of some diazeniumdiolates derivatives 
<smiles>NC(CCC(=O)NC(CSNO)C(=O)NCC(=O)O)C(=O)O</smiles><smiles>[3H]C(CNO)C(=O)O</smiles><smiles>[R]NC(=O)C(N)C(C)(C)SNO</smiles>

8

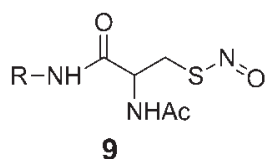

9

图 2 一些亚硝基硫醇的化学结构式

Fig.2 Chemical structures of some S-nitrosothiol derivatives

不能自发的释放 NO, 但能够在一些特定的条件下 分解产生 $\mathrm{NO}$ 。亚硝基硫醇可通过过渡金属(例如 $\mathrm{Cu}^{+}$)、抗坏血酸、紫外光、热、或者酶(超氧化物 歧化酶以及蛋白二硫化物异构酶) 等刺激释放 $\mathrm{NO}$ 。 亚硝基硫醇受到环境热的影响后, $\mathrm{S}-\mathrm{NO}$ 键均裂 生成 $\mathrm{NO}$ 和相应的二硫键。紫外光照射亚硝基硫醇 产生 $\mathrm{NO}$ 是由于紫外光诱导 $\mathrm{S}-\mathrm{NO}$ 键断裂, 产生一 分子 $\mathrm{NO}$, 同时亚硝基硫醇与均裂产生的硫醇自由 基反应生成另一分子 $\mathrm{NO}$ 。亚铜离子 $\left(\mathrm{Cu}^{+}\right)$催化分解 亚硝基硫醇释放 $\mathrm{NO}$ 生成 $\mathrm{Cu}^{2+}$ 和亚硝基硫醇的中间 化合物。然而, 抗坏血酸钠催化亚硝基硫醇分解 释放 NO 可分为两种机理。低浓度的抗坏血酸钠通 过还原生理环境中的二价 $\mathrm{Cu}^{2+}$ 生成 $\mathrm{Cu}^{+}$, 促进 $\mathrm{NO}$ 的释放。高浓度的抗坏血酸作为一种亲核试剂直 接进攻亚硝基, 促进 NO 的释放 ${ }^{20,31}$ 。

Balkus 等 ${ }^{32}$ 将半胱氨酸亚硝基硫醇修饰在光敏 剂硒化铅 $(\mathrm{PbSe})$ 表面, 在光的照射下, $\mathrm{NO}$ 的释放 效率相比较于半胱氨酸亚硝基硫醇提高了 9 倍, 并 且 $\mathrm{NO}$ 的释放可以有效地提高光敏剂产生单线态氧 $\left({ }^{1} \mathrm{O}_{2}\right)$ 的量子产率。Reynolds 等 ${ }^{33}$ 用一种金属有机框 架材料(MOF)均苯三甲酸铜 $\left(\mathrm{Cu}_{3}(\mathrm{BTC})_{2}\right)$ 作为催化剂 催化半胱氨酸亚硝基硫醇分解产生 $\mathrm{NO}$ 。当过量的 半胱氨酸亚硝基硫醇与 $\mathrm{Cu}_{3}(\mathrm{BTC})_{2}$ 中的 $\mathrm{Cu}^{+}$活性位 点相互作用, 催化产生 NO 的转化率几乎为 $100 \%$ 。在对照实验中, 加入不含 $\mathrm{Cu}^{+}$的 $\mathrm{MOF}$ 催化 剂, 没有 $\mathrm{NO}$ 产生, 说明含 $\mathrm{Cu}^{+}$的 $\mathrm{MOF}$ 催化剂能有 效地催化半胱氨酸亚硝基硫醇分解产生 $\mathrm{NO}$ 。 $\mathrm{Li}$ 等 ${ }^{34}$ 通过共价键将谷胱甘肽亚硝基硫醇修饰到 $\mathrm{Ag}_{2} \mathrm{~S}$ 量子点表面。在紫外光和可见光的照射下, 谷胱 甘肽亚硝基硫醇能迅速的释放 NO, 并且能够在活 体内近红外苂光成像。

\section{3 硝基苯类 $\left(\mathrm{PhNO}_{2}\right)$}

硝基苯类是最具代表性的光控释放 NO 的有机 供体(图 3), 这类硝基苯衍生物通常邻位是空间位 阻大的取代基团(如 $\mathrm{CF}_{3}$ 、甲基或芳烃 $)^{20}$ 。邻位大取 代基团的空间位阻作用导致苯环空间结构扭曲, 芳环的硝基与芳环平面垂直, 硝基上的氧原子的 $p$ 轨道与相邻芳环的 $p$ 轨道的基态和激发态重叠。在 光的照射下, 硝基通过光重排转化为亚硝基, 诱 导亚硝基中氧氮键 $\left(\mathrm{O}-\mathrm{NO}_{2}\right)$ 断裂生成 $\mathrm{NO}$ 。在生理 条件下, 硝基苯类衍生物具有热力学稳定性和光 控释放 NO 的性能。之前研究人员设计的硝基苯衍 生物只能在紫外光的照射下释放 NO, 并且紫外光 对于生物体的正常细胞有伤害作用 ${ }^{10,31}$ 。因此, 研 究人员设计在可见和近红外波段有吸收的硝基苯 衍生物 10-18。通过共价键将长波长的生色团修饰 到硝基苯衍生物上 ${ }^{35-40}$, 致使硝基苯衍生物在可见 光或近红外光照射下有效的释放 $\mathrm{NO}$ 。

Miyata 等 ${ }^{36,37}$ 将具有双光子吸收的荧光基团荧 光素通过共价键修饰到二甲基硝基苯上得到了双 光子活化的 $\mathrm{NO}$ 供体苂光素-硝基苯分子 $\mathbf{1 4}$ (FluDNB)。此化合物在黑暗条件下很稳定, 在双光子 $720 \mathrm{~nm}$ 的激光照射 $10 \mathrm{~min}$ 后, 有 $8.3 \%$ 的 Fluo-DNB 释放 NO。最近, Nakagawa 等 ${ }^{40}$ 设计了罗丹明修饰 的线粒体靶向的硝基苯衍生物 18 (Rol-DNB-mor)。 此分子是由硝基苯作为 $\mathrm{NO}$ 供体, 罗丹明作为生色 团, 在可见光 $(530-590 \mathrm{~nm})$ 的照射下, 此分子能够 快速释放 NO 并将 NO 靶向运输到人胚肾细胞 (HEK293)的线粒体中。

\section{4 金属亚硝酰化合物(M-NO)}

$\mathrm{NO}$ 是一种与金属离子配位能力很强的配体, 配位能力明显强于其它气体分子, 如 $\mathrm{O}_{2}$ 和 $\mathrm{CO}$ 。金 属亚硝酰化合物是一类具有光敏性的 $\mathrm{NO}$ 供体, 在 光的照射下, 光电子由金属离子的 $\pi$ 轨道跃迁到 $\mathrm{NO}$ 的 $\pi$ 反键轨道, 导致 $\mathrm{M}-\mathrm{NO}$ 迅速的释放 $\mathrm{NO}$ 。可 以通过改变 M-NO配体的结构或金属中心如铁 $(\mathrm{Fe}) 、$ 锰 $(\mathrm{Mn})$ 、钓 $(\mathrm{Ru})$ 和铬 $(\mathrm{Cr})^{15-17}$ 来调节诱导释放 $\mathrm{NO}$ 所需光的波长范围。目前, 最常用的金属类 $\mathrm{NO}$ 供体是以 $\mathrm{Ru}$ 和 $\mathrm{Fe}$ 为金属中心的亚硝酰化合物。

金属 $\mathrm{Ru}$ 亚硝酰化合物(图 4), 相对于其他金属 亚硝酰化合物更稳定, 更适合在生理条件下使 用。并且多齿配体配位的 $\mathrm{Ru}$ 亚硝酰化合物比单齿 配体配位的 $\mathrm{Ru}$ 化合物具有更好的稳定性。通常采 用的多齿配体有卟啉、席夫碱、多吡啶和甲酰胺 
<smiles>[R]c1cc([R])c2ccc3c4ccccc4c([R])c4ccc1c2c43</smiles>

1-nitroBaP(10): $\mathrm{R}_{1}=\mathrm{NO}_{2}, \mathrm{R}_{2}=\mathrm{R}_{3}=\mathrm{H}$

3-nitroBaP(11): $\mathrm{R}_{2}=\mathrm{NO}_{2}, \mathrm{R}_{1}=\mathrm{R}_{3}=\mathrm{H}$

6-nitroBaP(12): $\mathrm{R}_{3}=\mathrm{NO}_{2}, \mathrm{R}_{1}=\mathrm{R}_{2}=\mathrm{H}$<smiles>Cc1c(C#N)c(C)n2c1C(c1ccc(CN(c3ccc(O)c(CCC(=O)O)c3)[N+](=O)[O-])cc1)c1c(C)c(C#N)c(C)n1B(F)B2F</smiles>

15<smiles>Nc1ncnc2c1nc(SCCCCCNc1ccc([N+](=O)[O-])c(C(F)(F)F)c1)n2C1C[C@H](O)[C@@H]2C[C@@H]1O2</smiles>

17<smiles>COc1cc(/C=C/C=C/c2cc(OC)cc(OC)c2)cc(/C=C/c2ccc(C(=O)Nc3ccc(C4=C5C=CC(=O)C=C5Cc5cc(O)ccc54)c(C(=O)O)c3)cc2)c1</smiles>

16<smiles>Cc1cc(/C=C/c2ccc(C3=C4C=CC(=[N+]5CCCC5)C=C4Cc4cc(N5CCCC5)ccc43)c(C(=O)[O-])c2)cc(C)c1[N+](=O)[O-]</smiles>

图 3 一些硝基苯类衍生物的化学结构式

Fig.3 Chemical structures of some nitrobenzene derivatives

类等 ${ }^{15-17}$ 。然而, $\mathrm{Ru}$ 亚硝酰化合物一般在紫外光的 照射下释放 NO, 于是, Mascharak ${ }^{14,41,42}$ 和 Liu 等 ${ }^{43-45}$ 将金属 $\mathrm{Ru}$ 上直接配位在可见光或近红外光有吸收 的发色团, 如试卤灵、荧光素、氟嗍荧光染料 等, 使金属化合物的吸收波长红移。在可见光或 近红外光的照射下, 此类金属 $\mathrm{Ru}$ 亚硝酰化合物能 够快速的释放 $\mathrm{NO}$ 。例如, 金属 $\mathrm{Ru}$ 的亚硝酰化合 物 23 在可见光的照射下释放高浓度的 NO, 可以诱 导人乳腺癌细胞(MDA-MB-231)的调亡。

典型的金属 $\mathrm{Fe}$ 亚硝酰化合物有陆森黑盐 $\left(\mathrm{RBS},\left[\mathrm{Fe}_{4} \mathrm{~S}_{3}(\mathrm{NO})_{7}\right]\right)$, 陆森红盐 $\left(\mathrm{RRS},\left[\mathrm{Fe}_{2} \mathrm{~S}_{2}(\mathrm{NO})_{4}\right]_{2}\right)$ 和陆森红酯( $\mathrm{RES}, \mathrm{R}_{2}\left[\mathrm{Fe}_{2} \mathrm{~S}_{2}(\mathrm{NO})_{4}\right]_{2}$ )(图 5)。这几种 $\mathrm{Fe}$ 亚硝酰化合物是人工模拟天然存在的铁硫簇亚硝 酰化合物 ${ }^{12,13}$ 。由于此类化合物只能在紫外光的照 射下释放 NO, 所以研究人员 ${ }^{46-49}$ 试图通过将 RES
金属中心与染料生色团原卟啉(PPIX)和荧光素(Fluor)配位, 使此类化合物在可见光或近红外光的照 射下有效的释放 NO。

\section{NO 运输材料}

\section{1 脂质体}

脂质体是利用磷脂双分子层膜所形成的囊泡 包裹药物分子而形成的制剂。由于生物体质膜的 基本结构也是磷脂双分子层膜, 脂质体具有与生 物体细胞相类似的结构, 因此有很好的生物相容 性。除此之外, 脂质体制备相对简单, 制备脂质 体所用到的脂材毒性小, 生物相溶性好, 没有免 疫反应, 并且可以同时包裹脂溶性药物和水溶性 药物。所以脂质体逐渐成为药物载体领域研究的 一个热点 ${ }^{50-53}$ 。 


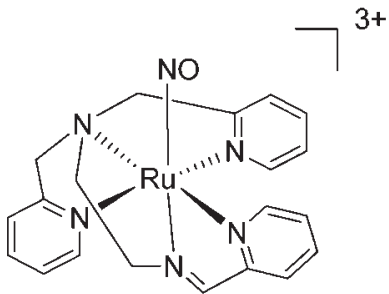

$\left.\left[\mathrm{SBPy}_{3}\right) \mathrm{Ru}(\mathrm{NO})\right]^{3+}(19)$

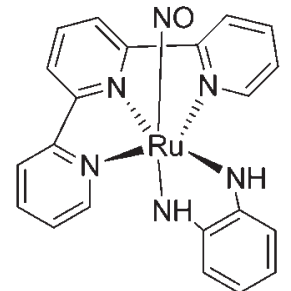

[(tpy)Ru(NH-NHph)(NO)]($\left(\mathrm{PF}_{6}\right)(21)$

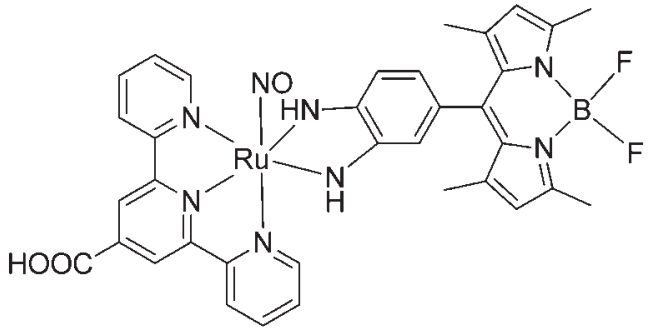

$\left[\left(\right.\right.$ tpy $\left.\left.^{\mathrm{COOH}}\right) \mathrm{Ru}(\mathrm{DAMBO})(\mathrm{NO})\right]\left(\mathrm{PF}_{6}\right)_{3}(20)$

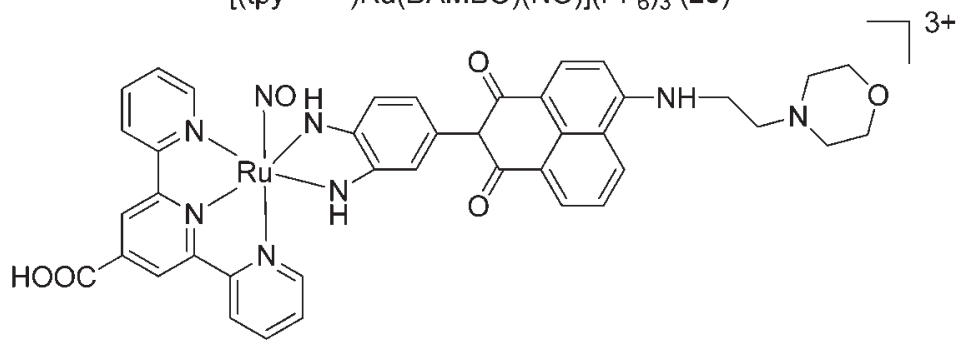

$\left[\left(\right.\right.$ tpy $\left.^{\mathrm{COOH}}\right) \mathrm{Ru}($ lyso-NINO) $(\mathrm{NO})]\left(\mathrm{PF}_{6}\right)_{3}(22)$

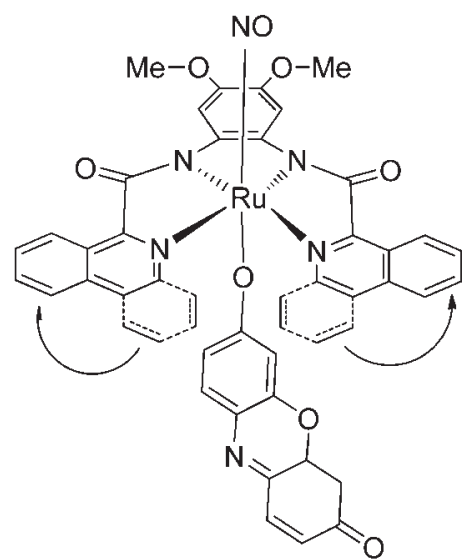

$\left[\left((\mathrm{OMe})_{2} \mathrm{IQ}\right) \mathrm{Ru}(\mathrm{NO})(\mathrm{Resf})\right](23)$

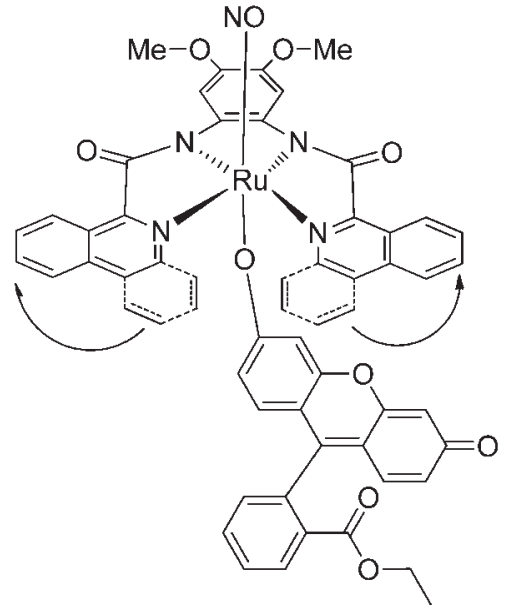

$\left[\left((\mathrm{OMe})_{2} \mathrm{IQ}\right) \mathrm{Ru}(\mathrm{NO})(\mathrm{FIEt})\right](24)$

图 4 一些金属 Ru亚硝酰化合物的化学结构式

Fig.4 Chemical structures of some ruthenium nitrosyls

Yang 等 ${ }^{54}$ 将两亲的精胺-偶氮二醇烯盐包覆在 温敏性的脂质体中, 为了阻止精胺-偶氮二醇烯自 发释放 NO, 在载入空的脂质体之前, 将精胺-偶氮 二醇烯溶于碱性缓冲溶液中。在加热的条件下, 载入 $\mathrm{NO}$ 供体的温敏型脂质体的磷脂双分子层的通 透性发生变化, 脂质体内 $\mathrm{pH}$ 值下降, 诱导偶氮二 醇烯水解释放 $\mathrm{NO}$ 。除了加热, 在强酸条件下, $\mathrm{H}^{+}$ 进入脂质体内部也会导致 $\mathrm{NO}$ 的迅速释放。研究人 员 ${ }^{55,56}$ 也将光敏性的金属 $\mathrm{Cr}$ 的亚硝酰化合物 trans$\mathrm{Cr}(\mathrm{L})(\mathrm{ONO})_{2}^{+}(\mathrm{L}=$ 大环四胺 $)$ 包覆在脂质体内部。在 $470 \mathrm{~nm}$ 可见光的照射下, 此脂质体会迅速的释放 NO (图 6(a))。最近, Koshiyama等 ${ }^{57}$ 设计了一种新
的 $\mathrm{Ru}$ 亚硝酰化合物 $[\mathrm{Ru}(\mathrm{L}) \mathrm{Cl}(\mathrm{NO})]\left(\mathrm{L}=N, N^{\prime}\right.$-乙烯 基-双(4-胆甾醇基-半琥珠酸酯-邻着亚苄基胺)), 通 过胆固醇和磷脂双分子层的疏水性相互作用将 $\mathrm{Ru}$ 亚硝酰化合物固定在脂质体的磷脂双分子层。这 个设计能够巧妙地将疏水性的 $\mathrm{Ru}$ 亚硝基化合物应 用于生理环境中。在可见光的照射下, 此体系在 生理环境中迅速地释放 $\mathrm{NO}$ (图 6b)。

\section{2 二氧化硅纳米粒子 $\left(\mathrm{SiO}_{2}\right)$}

二氧化硅纳米粒子已成为一种具有潜力的药 物载体。它们的优势包括粒子大小可控、易于制 备、功能化简单、良好的稳定性和生物兼容 性 ${ }^{58-65}$ 。近期, 研究人员通过溶胶-凝胶的方法制备 


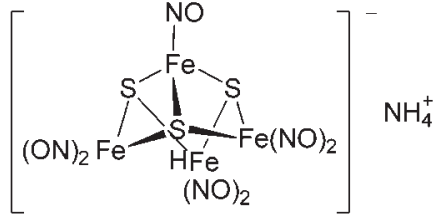

RBS (25)

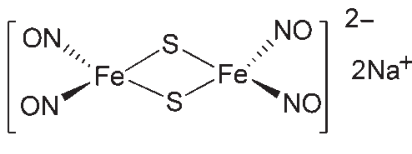

RRS (26)<smiles>[R][SH]1[P+]([N+](=O)[O-])[P-]([N+](=O)[O-])[SH]1[R]</smiles>

RES (27)

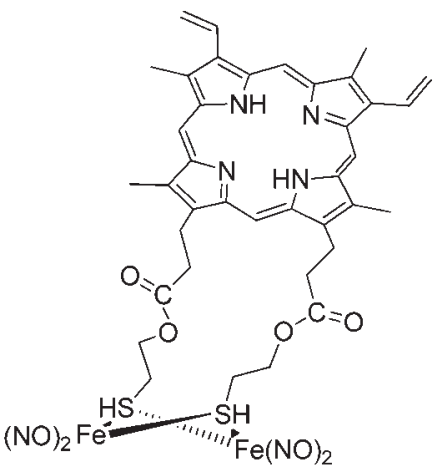

PPIX-RSE (28)

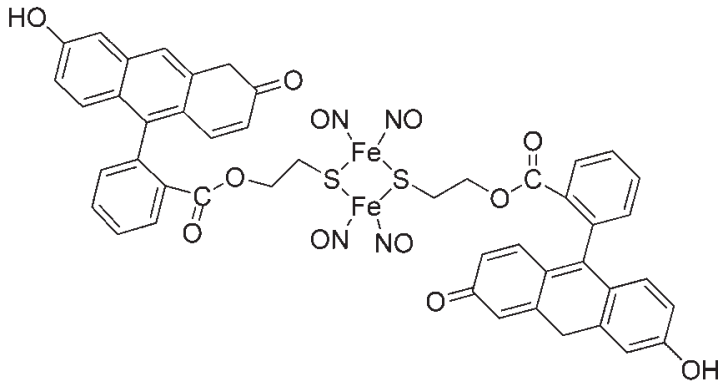

Fluor-RSE (29)

图 5 一些金属 $\mathrm{Fe}$ 亚硝酰化合物的化学结构式

Fig.5 Chemical structures of some iron nitrosyls

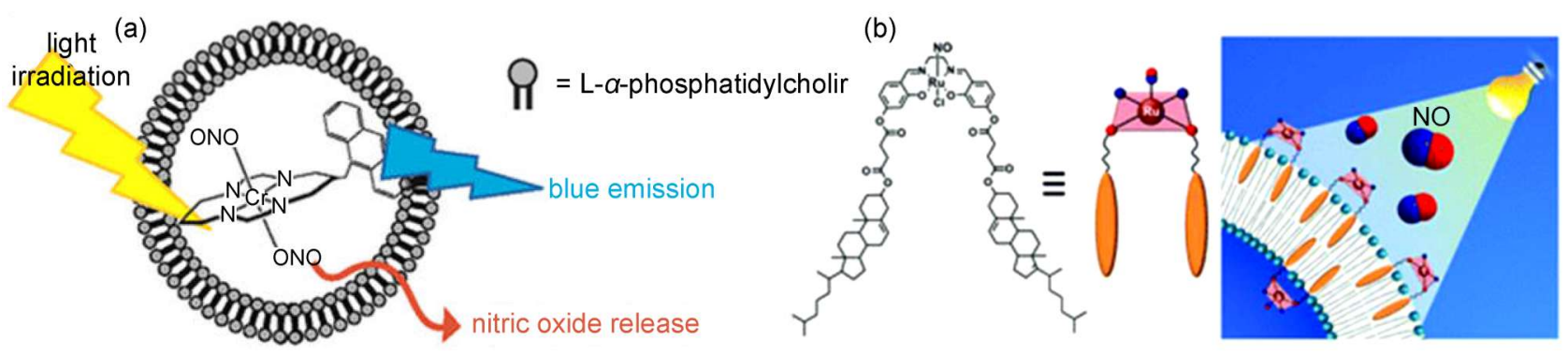

图 6 以脂质体为载体的 NO 运输平台 ${ }^{55,57}$

Fig.6 Schematic illustration of liposome-based NO-releasing nanosystems $\mathbf{s}^{5,57}$

Incorporation of (a) Chromium nitrosyl, trans-Cr(L)(ONO) ${ }_{2}^{+}\left(\mathrm{L}\right.$, cyclam $=1,4,8,11$-tetraazacyclotetradecane ${ }^{55}$, and (b) Ruthenium nitrosyl,

$[\mathrm{Ru}(\mathrm{L}) \mathrm{Cl}(\mathrm{NO})]\left(\mathrm{L}=N, N^{\prime}\right.$-ethylene-bis(4-cholesteryl-hemisuccinate-salicylideneamine) into liposomes ${ }^{57}$

出负载有各种 $\mathrm{NO}$ 供体(例如偶氮二醇烯类、金属 亚硝酰化合物和亚硝基硫醇类)的二氧化硅纳米粒 子。

Meyerhoff 等 ${ }^{6}$ 制备出偶氮二醇烯功能化的 $\mathrm{SiO}_{2}$ 纳米粒子。他们将一系列的氨基取代的烷基硅 烷通过溶胶-凝胶的方法修饰到 $\mathrm{SiO}_{2}$ 表面, 接着将 二级胺转化成偶氮二醇烯。此类偶氮二醇烯盐分 解释放 NO 的速率容易受到偶氮二醇烯盐氨基结构 和 $\mathrm{pH}$ 的影响, 并且这种方法很难控制纳米粒子的 大小。因此, Schoenfisch 等 ${ }^{67-69}$ 报道了可以调控 $\mathrm{SiO}_{2}$ 的尺寸大小和优化 $\mathrm{NO}$ 释放性能的方法。此种 方法是将四甲氧基硅烷或四乙氧基硅烷与氨基取 代的烷氧基硅烷共聚制备氨基功能化的纳米 $\mathrm{SiO}_{2}$,
然后将 $\mathrm{SiO}_{2}$ 表面的二级胺转化为偶氮二醇烯盐。 通过改变四烷氧基硅烷和氨基取代的烷氧基硅烷 的结构和浓度可以控制纳米粒子的大小在 20-500 $\mathrm{nm}$ 。

此外, 介孔二氧化硅材料所具有的大比表面 积, 较高的孔隙率, 规整有序的孔道结构, 均一 可调的孔径以及无生理毒性等优点使其成为药物 的优良载体，可以提高 NO 供体的负载量 ${ }^{70,71}$ 。 Schoenfisch 等 ${ }^{72}$ 开发出不同大小和形状的修饰有偶 氮二醇烯盐的介孔 $\mathrm{SiO}_{2}$ 纳米粒子。 $\mathrm{NO}$ 的释放速率 和抗菌能力可由介孔孔径的比例来调节。在生理 条件下，修饰有偶氮二醇烯的介孔 $\mathrm{SiO}_{2}$ 纳米粒子 相对于普通的载有偶氮二醇烯的 $\mathrm{SiO}_{2}$ 纳米粒子具 
有更高的稳定性和更持久的释放 $\mathrm{NO}$ 半衰期 ${ }^{73}$ 。最 近, $\mathrm{Kim}$ 等 ${ }^{74}$ 结合介孔 $\mathrm{SiO}_{2}$ 纳米粒子和磷酸钙涂层 设计了一种光控释放 NO 的纳米体系(图 7(a))。在 光的照射下, 产生的酸可以被用来刺激开关的打 开, 导致偶氮二醇烯盐释放 $\mathrm{NO}$ 。酸的产生将加速 介孔 $\mathrm{SiO}_{2}$ 表面涂层的降解, 从而方便 $\mathrm{NO}$ 供体偶氮 二醇烯盐暴露在生理条件下, 水解释放 NO。此种 光刺激释放 NO 的体系可用来修复受伤的眼角膜。 但是, 此体系需要依靠紫外光来刺激 NO 的产生, 从而限制了其在生物体的应用。

除了偶氮二醇烯类, 其它种类的 $\mathrm{NO}$ 供体也可 以被修饰到介孔二氧化硅表面和孔道, 如亚硝基 硫醇和金属 $\mathrm{Mn}$ 的亚硝酰化合物 ${ }^{75}-77$ 。与偶氮二醇 烯修饰方法相似, Meyerhoff ${ }^{76}$ 和 Schoenfisch ${ }^{77}$ 等将 $\mathrm{SiO}_{2}$ 表面嫁接含有颈基的分子, 接着放基进行硝基 化, 最终得到含有亚硝基硫醇的 $\mathrm{SiO}_{2}$ 纳米粒子。 此种方法制备的纳米粒子在光、热和金属离子的 刺激下会释放 NO。Mascharak 等 ${ }^{75}$ 用一种商用的介 孔 $\mathrm{SiO}_{2}$ 纳米粒子 $\mathrm{MCM}-41$ 作为载体, 通过 MCM-41 上的羟基和带正电的金属 $\mathrm{Mn}$ 亚硝酰化合物 $[\mathrm{Mn}$ $\left.\left(\mathrm{PaPy}_{3}\right)(\mathrm{NO})\right]\left(\mathrm{ClO}_{4}\right)$ 的强烈相互作用, 制备载有光 敏性金属 $\mathrm{Mn}$ 亚硝酰化合物的介孔 $\mathrm{SiO}_{2}$ 纳米粒子 (图 7(b))。此种纳米粒子在近红外光 $(600 \mathrm{~nm}$ ) 的照 射下, 能够迅速的释放 NO。如果将此种材料周期 性地在 $600 \mathrm{~nm}$ 光下照射会导致 NO 的脉冲性释 放, 表明此材料的 $\mathrm{NO}$ 释放完全由光控制。此外, 此种载有 NO 载体的 MCM-41 的材料在光的照射 下, 能够有效地清除软组织感染模型中抗药和耐 药性的鲍氏不动杆菌。

\section{3 量子点(QDs)}

QDs 具有激发光谱宽而连续、发射光谱窄而
对称、发光效率高、光化学稳定性好、不易发生 光漂白、发射光颜色与粒径大小关联等优点, 被 广泛应用于蛋白质及 DNA 检测、细胞标记成像、 活细胞生命动态过程示踪、活体体内肿瘤细胞靶 向示踪等生物医学领域 ${ }^{78-82}$ 。Ford 等 ${ }^{83-85}$ 制备了水 溶性的核壳结构硒化镉 - 硫化锌量子点 (CdSe$\mathrm{ZnS}$ ), 通过静电作用将带正电的金属 $\mathrm{Cr}$ 亚硝酰化 合物负载在带负电的量子点表面(图 8(a))。在紫外 光 $(320-390 \mathrm{~nm})$ 的照射下, 此组装体能够迅速的产 生大量的 $\mathrm{NO}$ 。但是, 由于量子点自身毒性大等因 素，限制了此类体系在生物体的进一步应用。

$\mathrm{Li}$ 等 ${ }^{34}$ 报道了一种新的光控释放 $\mathrm{NO}$ 的纳米体 系硫化银-谷胱甘肽-亚硝基硫醇 $\left(\mathrm{Ag}_{2} \mathrm{~S}-\mathrm{GSH}-\mathrm{SNO}\right)$ (图 8(b))。此纳米体系在紫外或可见光的照射下释 放 $\mathrm{NO}$, 并且具有近红外荧光成像的功能。 $\mathrm{Ag}_{2} \mathrm{~S}$ 量 子点是通过一步合成法合成的, 谷胱甘肽既作为 硫源也作为稳定剂。亚硝基硫醇通过与谷胱甘肽 上的氨基相连, 从而修饰到 $\mathrm{Ag}_{2} \mathrm{~S}$ 量子点表面。此 纳米粒子在紫外和可见光的照射下, 在细胞和动 物体内均能释放 $\mathrm{NO}$ 。但在近红外光的照射下基本 上不释放 $\mathrm{NO}$ 。除此之外, 此纳米体系能够在活体 内近红外苂光成像。之后, $\mathrm{Li}$ 等 ${ }^{86}$ 合成了负载有 $\mathrm{NO}$ 供体的纳米体系锰离子掺杂的硫化锌@壳聚糖陆森黑盐 $\left(\mathrm{Mn}^{2+}-\mathrm{ZnS} @ \mathrm{CS}-\mathrm{RBS}\right.$ ) (图 8(c))。此纳米化 合物在 $1060 \mathrm{~nm}$ 光的照射下释放 $\mathrm{NO}$, 具有较长的 荧光寿命, 显著的斯托克位移以及良好的光稳定 性, 在生物应用上显示出了极大的潜能。

\section{4 上转换发光稀土材料(UCNPs)}

上转换发光稀土材料(UCNPs) 是一种能将低能 量的光子转换成高能量光子的反斯托克发光的功 能材料。上转换发光材料的最大特点是材料所吸

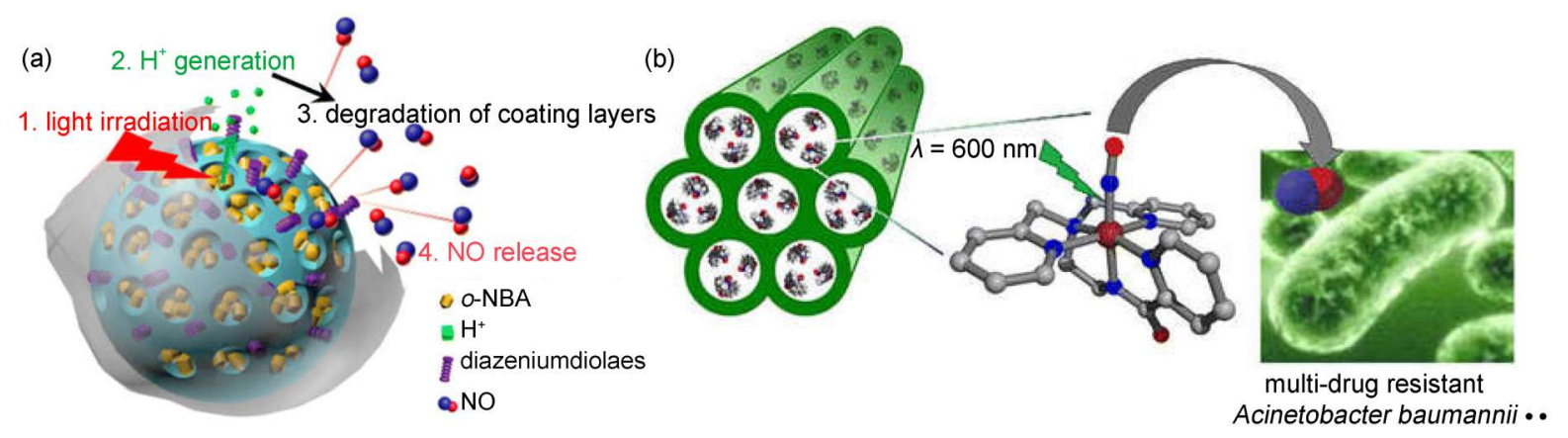

图 7 以 $\mathrm{SiO}_{2}$ 为载体的 $\mathrm{NO}$ 纳米平台 ${ }^{74,75}$

Fig.7 Schematic illustration of $\mathrm{SiO}_{2}$-based NO-releasing nanosystems ${ }^{74,75}$

(a) schematic model of light-induced acid generation on gatekeeper for smart $\mathrm{NO}$ delivery ${ }^{74}$,

(b) photoactive manganese nitrosyl loaded into columnar pores of an MCM-41 host ${ }^{75}$ 

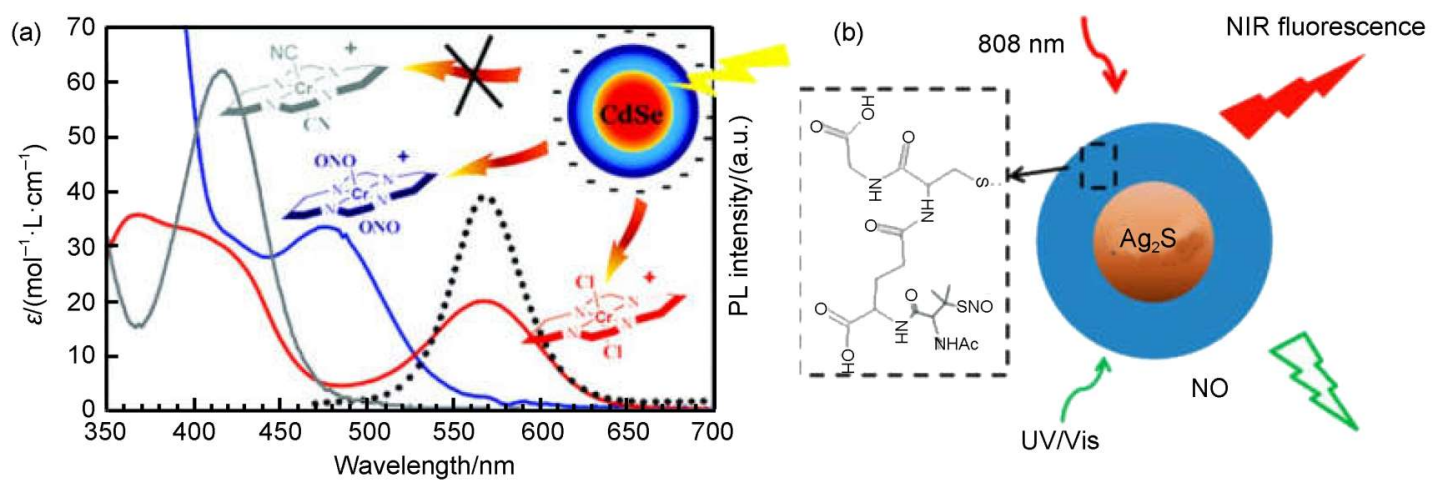

(c)

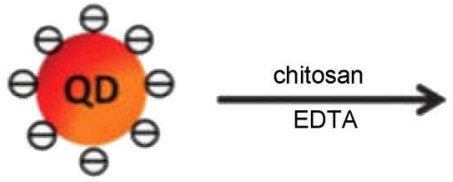

$\mathrm{Mn}^{2+}$-doped ZnS QDS

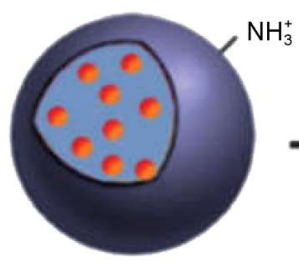

$\mathrm{Mn}^{2+}-\mathrm{ZnS} @ \mathrm{CS}$

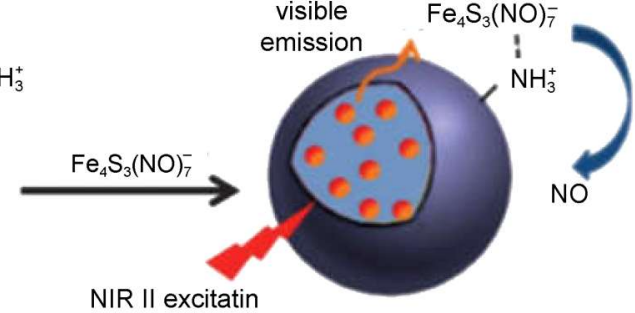

$\mathrm{Mn}^{2+}-\mathrm{ZnS} @ C S-R B S$

图 8 光控制释放量子点为载体的 NO 纳米平台 ${ }^{34,84,86}$

Fig.8 Schematic illustration quantumn dots (QDs)-based NO-releasing nanosystem ${ }^{34,84,86}$ (a) cadmium selenide/zinc sulfide@chromium(III) complexes CdSe/ZnS@trans-Cr(cyclam)(ONO) ${ }^{2+}{ }^{84}$, (b) silver sulfide- glutathione-S-nitrosothiol $\left(\mathrm{Ag}_{2} \mathrm{~S}-\mathrm{GSH}-\mathrm{SNO}\right)$ nanoparticles ${ }^{34}$, (c) manganese-dopedzinc sulfide@ chitosan-Roussin's black salt (Mnn $\left.{ }^{2+}-\mathrm{ZnS} @ \mathrm{CS}-\mathrm{RBS}\right)$ nanoparticles $^{86}$

收的光子能量低于发射的光子能量。相比于传统 的荧光探针, 例如有机染料、荧光蛋白和量子 点, 上转换发光物质具有众多的优势, 如狭窄的 发射带宽、长的发光寿命、可调节的发射光谱、 高的光稳定性以及相对低的细胞毒性。很多研究 致力于合成高发光性能的稀土上转换发光纳米材 料, 将它们应用于生物标记、细胞成像、病变检 测、DNA 检测、生物传感以及结合光敏剂用于光 动力和光热治疗。稀土上转换发光纳米材料在生 物医学上具有很大的应用潜力。当前存在的 $\mathrm{NO}$ 供 体都是在紫外光或者可见光的照射下释放 $\mathrm{NO}$ 。但 是, 紫外光具有差的组织穿透能力和对健康细胞 具有毒害作用, 这些缺点限制了大多数 NO供体在 体内的进一步应用 ${ }^{87,88}$ 。Zhang 等 ${ }^{89}$ 制备出了表面包 有 $\mathrm{SiO}_{2}$ 的核壳结构 UCNPs (UCNP@SiO 2 )。此种材 料表面带有正电荷, 带有负电荷的铁硫簇亚硝酰 化合物陆森黑盐 $\mathrm{Fe}_{4} \mathrm{~S}_{3}(\mathrm{NO})_{7}^{-}(\mathrm{RBS})$ 可以通过静电相 互作用吸附在 UCNP@ $\mathrm{SiO}_{2}$ 的表面。由于 $\mathrm{RBS}$ 的吸 收光谱与 UCNPs 的发射光谱有重叠, 在近红外光 $980 \mathrm{~nm}$ 的照射下, UCNPs 将 $980 \mathrm{~nm}$ 的近红外光转 化为 $550 \mathrm{~nm}$ 的可见光, 刺激 RBS 控制释放 NO。

Ford 等 ${ }^{90}$ 使用 UCNPs 设计出了近红外光控制 释放 NO 的材料, 上转化材料_陆森黑盐-聚合圆盘
(UCNP_RBS_PD), 并利用此材料在近红外光的聚 焦光束下控制释放 NO, 以减小局部过热导致的危 害(图9(a))。UCNP_RBS_PD是由聚二甲基硅烷和 UCNPs 形成的具有生物兼容性的聚合物圆盘, 聚 合物圆盘中镶嵌有光敏性的 NO供体 RBS。近红外 光穿过猪皮组织照射UCNP_RBS_PD 时, 仍然能 够释放达到生理条件需要的 NO 浓度, 说明此种材 料具有能够应用于生理环境的潜能。

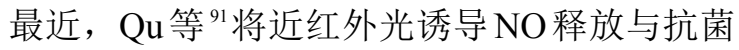
化合物结合制备出了一类纳米体系陆森黑盐@上转 化材料@介孔二氧化硅@聚季铵盐(RBS@UC$\left.\mathrm{NP} @ \mathrm{mSiO}_{2} @ \mathrm{qC}\right)$ 。此纳米体系能够增加生物膜的 分散, 防止再生和减小副作用的效果。该体系是 将 RBS 和阳离子聚合物负载在 UCNPs 的表面。 UCNPs 用来吸收近红外光并转化成特定波长的可 见光, 刺激 $\mathrm{NO}$ 的释放。合成的阳离子聚合物氨基 壳聚糖能够破坏病原体细胞质膜, 通过 $\mathrm{NO}$ 与阳离 子聚合物的协同作用, 达到抗菌的作用。另外, 此种纳米体系具有良好的生物兼容性, 能够在近 红外光的照射下在活体内去除抗药性的细菌, 在 抗菌领域显示出了很大的潜能。

Shi 等 ${ }^{2}$ 首次构建了 $\mathrm{X}$ 射线控制释放的纳米体 系, 聚乙二醇-上转化材料 - 亚硝基硫醇 (PEG- 

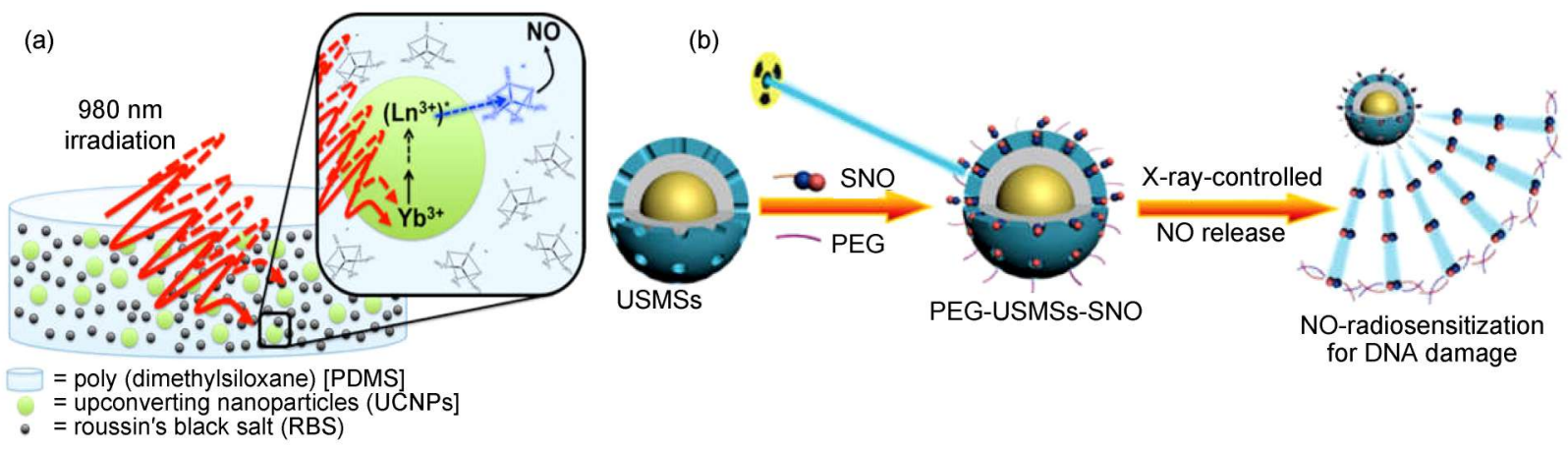

图 9 上转换材料作为近红外光控制释放 NO 的纳米平台 ${ }^{90,92}$

Fig.9 Schematic illustration of UCNPs-based NO-releasing nanosystems ${ }^{90,92}$

(a) NIR light excitation of upconverting nanoparticles_roussin's black salt_poly(dimethylsiloxane) (UCNP_RBS_PD) ${ }^{90}$, (b) X-ray-controlled NO release ${ }^{92}$

USMSs-SNO)。首先合成 UCNP@ $\mathrm{SiO}_{2}$ 纳米结构, 然后将生物兼容性的聚乙二醇(PEG)和 NO 供体亚 硝基硫醇(SNO)修饰到此纳米结构表面(图9b)。此 纳米体系可同时实现上转换荧光成像和放射治疗 缺氧环境下的肿瘤。在 $X$ 射线的照射下, 表面的 亚硝基硫醇的 $\mathrm{S}-\mathrm{N}$ 键断裂导致 $\mathrm{NO}$ 释放, 并且 $\mathrm{NO}$ 的释放量是由 $\mathrm{X}$ 射线的照射时间和强度决定的。 研究结果表明, 纳米体系 PEG-USMSs-SNO 不管在 正常或者缺氧细胞里还是斑马鱼活体内都能实现 X 射线控制释放 $\mathrm{NO}$ 。并且, 释放的 $\mathrm{NO}$ 能够导致缺 氧肿瘤细胞死亡和抑制固体肿瘤的增长。

Zhao 等 ${ }^{93}$ 成功合成了一种上转换纳米材料-陆 森黑盐的纳米体系 $\left(\mathrm{NaYbF}_{4}: \mathrm{Tm} @ \mathrm{NaYF}_{4}: \mathrm{Yb} /\right.$ Er@RBS)。介孔二氧化硅包覆的纳米体系可以作 为近红外光敏剂, 其中含 $\mathrm{Fe}$ 络合物的陆森黑盐 $\left[\mathrm{NH}_{4}\right]\left[\mathrm{Fe}_{4} \mathrm{~S}_{3}(\mathrm{NO})_{7}\right](\mathrm{RBS})$ 作为光敏性的 $\mathrm{NO}$ 供体。介 孔二氧化硅可以有效地将 RBS 吸附到 UCNPs 的表 面, 同时 UCNPs 的发射波长与 RBS 的吸收波长相 重合, 从而能够利用调节激光的输出功率来控制 释放所需求量的 $\mathrm{NO}$ 。由于不同浓度的 $\mathrm{NO}$ 在生理 过程中发挥不同的作用, 他们 ${ }^{93}$ 利用高强度的近红 外激光照射该体系释放高浓度的 $\mathrm{NO}$, 直接导致肿 瘤细胞的死亡。低强度的激光照射诱导产生的低 浓度 NO 虽然不能直接杀死癌细胞, 但是可以有效 的抑制 P-糖蛋白在多重抗药性肿瘤细胞膜的表 达, 从而实现在化学疗法中克服多重抗药性的作 用。

\section{5 二氧化钛 $\left(\mathrm{TiO}_{2}\right)$}

二氧化钛纳米粒子具有独特的光催化性质、 良好的生物兼容性、价格低廉、较低的细胞毒
性、良好的热稳定性和化学稳定性等优点, 因而 广泛的应用于生物医学领域, 如光动力学治疗、 药物运输以及细胞成像等。但是在实际生物应用 过程中, 由于二氧化钛是一种宽禁带半导体, 其 禁带宽度为 $3.2 \mathrm{eV}$ (锐钛矿), 只有在紫外光的激发 下才能表现出光催化活性。然而紫外光穿透组织 能力差并对生物体有害, 因此对二氧化钛进行改 性, 使其在可见光或者近红外光的照射下显示光 催化活性是目前的一个研究热点 ${ }^{94-97}$ 。

2011 年, Balkus 等 ${ }^{32}$ 设计了一种新型的 $\mathrm{TiO}_{2}$ 纳 米复合体 $(\mathrm{PbS} / \mathrm{TNTs} / \mathrm{Cys}-\mathrm{NO}$ ) (图 10(a))。该体系是 由 $\mathrm{NO}$ 光供体半胱氨酸-NO (cysteine-NO), 近红外 光敏剂硫化铅量子点 $(\mathrm{PbSQDS})$ 和光催化剂 $\mathrm{TiO}_{2}$ 纳 米管组成的。此纳米复合体能够在 $600 \mathrm{~nm}$ 的近红 外光的照射下释放 NO, 并且释放的 $\mathrm{NO}$ 能够促进 单线态氧的产生。近期, $\mathrm{Liu}$ 等 ${ }^{43}$ 开发了多功能纳 米复合物 $\left(\mathrm{Ru}-\mathrm{NO} @ \mathrm{TiO}_{2} \mathrm{NPs}\right.$ ) (图 10(b))。此纳米复 合物是由 $\mathrm{NO}$ 供体 $\mathrm{Ru}$ 亚硝酰化合物 $\left[\mathrm{Ru}\left(\mathrm{tp} \mathrm{y}^{\mathrm{COOH}}\right)\right.$ $(\mathrm{DAMBO}) \mathrm{NO}]\left(\mathrm{PF}_{6}\right)_{3}$ 和靶向分子叶酸 $(\mathrm{FA})$ 通过共价 键的作用负载在 $\mathrm{TiO}_{2}$ 载体表面。 $\mathrm{Ru}-\mathrm{NO} @ \mathrm{TiO}_{2} \mathrm{NPs}$ 在黑暗条件下具有良好的稳定性。在细胞中能够 靶向叶酸接收器过度表达的肿瘤细胞, 如 HeLa 细 胞。此外, 由于此纳米体系在 $520 \mathrm{~nm}$ 处有很强的 吸收, 在可见光的照射下, 此纳米复合物能够同 时释放高浓度的 $\mathrm{NO}$ 和单线态氧 $\left(\mathrm{O}_{2}\right)$ 从而诱导肿瘤 细胞的早期凋亡。在此基础上, Liu 等 ${ }^{44}$ 制备出在 近红外光响应的、能够同时释放 $\mathrm{NO}$ 和 ${ }^{1} \mathrm{O}_{2}$ 的纳米 复合体系(Lyso-Ru-NO@FA@C-TiO $)$ (图 10(c))。该 体系是由具有溶酶体靶向基团的 NO 光供体 Lyso$\mathrm{Ru}-\mathrm{NO}$ 和靶向分子 FA 通过共价键修饰在在近红外 


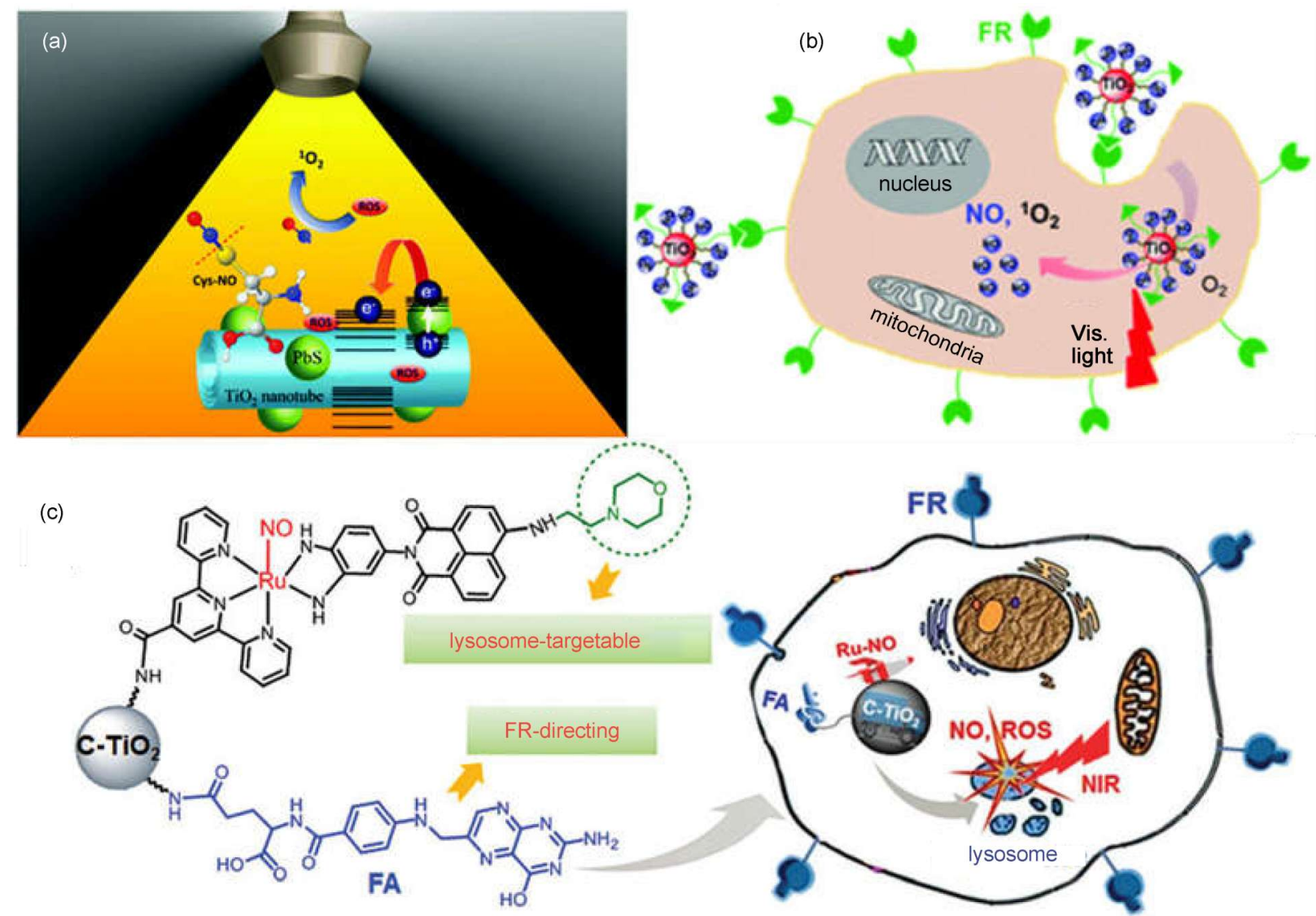

\{Lyso-Ru-NO@FA@C-TiO $\left.{ }_{2}\right\}$ (1)

图 10 二氧化钛作为光控释放 NO 的纳米平台 ${ }^{32,43,44}$

Fig.10 Schematic illustration of $\mathrm{TiO}_{2}$-based NO-releasing nanosystems s $^{32,43,44}$

(a) S-nitrosocysteine-decorated lead sulfide quantum dots/titanium dioxide $\left(\mathrm{PbS} \mathrm{QDs} / \mathrm{TiO}_{2}\right)$ nanotubes for the production of NO and singlet oxygen $\left({ }^{1} \mathrm{O}_{2}\right)^{32}$, (b) ruthenium nitrosyls@ titanium dioxide nanoparticles (Ru-NO@ $\left.\mathrm{TiO}_{2} \mathrm{NPs}\right)$ for target-directing delivery of $\mathrm{NO}$ and ${ }^{1} \mathrm{O}_{2}$ to specific cancer cells $^{43}$, (c) ruthenium nitrosyls@folic acid@carbon doped titanium dioxide (Lyso-Ru-NO@FA@C-TiO ${ }_{2}$ ) for directed attack of cancer cell lysosomes by NO and reactive oxygen species (ROS) under NIR light irradiation ${ }^{44}$

有吸收的碳掺杂 $\mathrm{TiO}_{2}$ 表面。此纳米复合体系能够 靶向叶酸接收器过度表达的 HeLa 细胞溶酶体。在 $808 \mathrm{~nm}$ 近红外光的激发下, 同时释放的 $\mathrm{NO}$ 和 ${ }^{\mathrm{I}} \mathrm{O}_{2}$ 会导致肿瘤细胞的死亡。

\section{6 碳材料}

与传统半导体发光材料相比, 荧光碳点作为 一种新型的碳纳米发光材料, 因其优异的生物相 容性、良好的发光性能、简单的合成工艺、低廉 的成本等优点而备受关注。苂光碳点在生物苂光 标定、医学传感器、光诊疗剂以及发光器件等方 面具有广阔的应用潜力 ${ }^{98-100}$ 。Wu 等 ${ }^{101}$ 成功开发了 以碳点作为载体, 亚硝基硫醇为 $\mathrm{NO}$ 光供体, 三苯 基磷为靶向基团的光控释放 $\mathrm{NO}$ 的纳米体系。此纳 米体系在可见光的照射下能够长时间的释放 NO, 并且靶向亚细胞器线粒体。相对于非靶向体系,
此纳米体系具有促进细胞调亡的作用。最近, Callan 等 ${ }^{102}$ 结合碳点和 $\mathrm{NO}$ 光供体硝基苯衍生物开 发出了双光子激光诱导释放 NO 的纳米结构。此纳 米体系能够有效的吸收 $800 \mathrm{~nm}$ 双光子能量并转移 至 $\mathrm{NO}$ 光供体, 激发硝基苯衍生物有效地释放 $\mathrm{NO}$ 。CQDs-NO纳米共轭体系在黑暗条件下具有良 好的生物兼容性。在 $800 \mathrm{~nm}$ 双光子的照射下, 产 生高浓度的 NO, 促使 HeLa 细胞调亡并且能够抑 制缺氧BxPC-3 肿瘤的增长(图 11)。

近期, Liu 等 ${ }^{45,103}$ 设计了一个多功能的释放 NO 的纳米平台(Lyso-Ru-NO@FA@CDs) (图 11)。Lyso- Ru-NO 是具有溶酶体靶向的光敏性 NO 光供 体。碳点可作为药物载体以及光热试剂, 并且可 以利用碳点自身的绿色荧光进行苂光成像。叶酸 (FA) 可将 $\mathrm{NO}$ 靶向释放到叶酸接收器过度表达的肿 

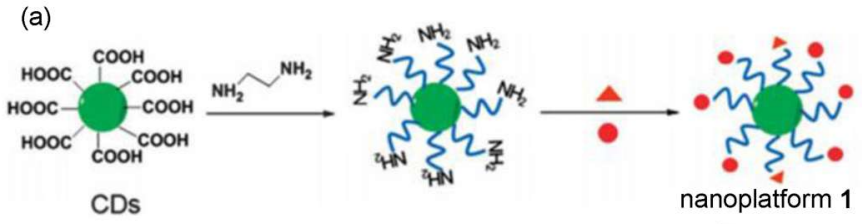

(b)
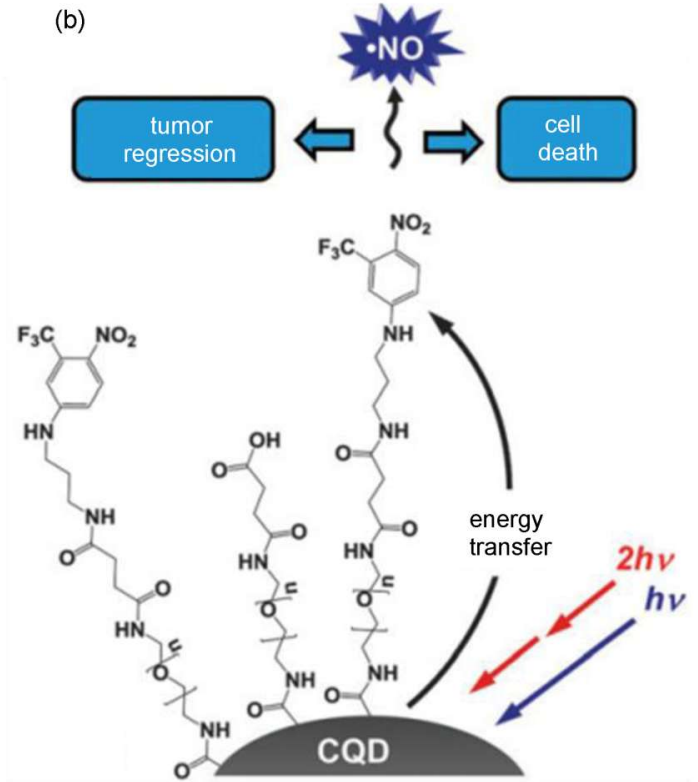

图 11 碳量子点作为光控释放 NO 的纳米平台 ${ }^{45,102}$

Fig.11 Schematic illustration of Carbon $\operatorname{dot}(\mathrm{CDs})$-based NO-releasing nanosystems ${ }^{45,102}$

(a) preparation of ruthenium nitrosyl@folic acid@carbon dots (Lyso-Ru-NO@FA@CDs) and its directed attack of cancer cell lysosomes by NO and photothermal therapy under irradiation with $808 \mathrm{~nm}$ light ${ }^{45}$, (b) NO photoreleasing carbon quntanum dots-nitrobenzene $(\mathrm{CQDs}-\mathrm{NO})^{102}$

瘤细胞中, 如 HeLa细胞。研究结果表明, 此纳米 平台能够靶向叶酸接收器过度表达的肿瘤细胞溶 酶体。在 $808 \mathrm{~nm}$ 近红外光的照射下, 快速释放出 来的高浓度 $\mathrm{NO}$ 与碳点产生的高热协同相互作用, 促使肿瘤细胞的有效调亡。与非靶向纳米体系相 比, 此纳米体系显示出了促进肿瘤细胞凋亡的效 果。

氧化石墨烯 $(\mathrm{GO})$ 是石墨烯的氧化产物, 含有 大量的羟基、羧基和环氧基团。这些含氧活性基 团的引入不仅使其拥有良好的水溶性和稳定性, 而且可使 GO 更易于修饰达到功能化的作用。除此 之外, GO 两面均具有芳香结构, 且比表面积较 大, 可通过 $\pi-\pi$ 共轭、氢键和疏水效应等非共价 键与 $\mathrm{NO}$ 供体结合 ${ }^{104-106}$ 。Chen 等 ${ }^{107}$ 首次使用氧化石 墨烯作为 $\mathrm{NO}$ 光控释放的载体, 通过 $\pi-\pi$ 共轭作用 将氧化石墨烯与 NO 供体 BNN6 形成组装体。氧化 石墨烯吸收近红外光将电子转移到 $\mathrm{NO}$ 光供体, 导 致 BNN6 分解释放 NO。最近, Sortino 等 ${ }^{108}$ 通过共 价键作用将 NO 供体 NOP 利用酰胺键修饰到 GO 的 表面, 形成一个新型的纳米体系 GO-NOP1。GONOP1 具有良好的水溶性, 在黑暗条件下很稳定, 但在可见光的照射会激发 NO 的产生。

\section{4 总结和展望}

自从发现 NO 具有调节血管扩张的作用后, 研 究人员设计和开发了许多外源的 NO 供体。然而, $\mathrm{NO}$ 供体结合药物运输载体在生物医学上的研究仅 仅开始于 2000 年。本综述主要总结和讨论了 $\mathrm{NO}$ 供 体以及 $\mathrm{NO}$ 供体结合几类药物载体组装形成的 $\mathrm{NO}$ 运输平台在生物医学领域的潜在应用。尽管 $\mathrm{NO}$ 运 输平台相对于 $\mathrm{NO}$ 供体在生物医学上具有更广的应 用前景, 但是每个 NO传输体系都有其自身的优点 和缺陷。例如, $\mathrm{NO}$ 运输平台在运输 $\mathrm{NO}$ 过程中的 最大问题是在未到达指定地点就开始释放 $\mathrm{NO}$ 。与 之相似的是, 负载 $\mathrm{NO}$ 供体的 $\mathrm{NO}$ 传递平台由于载 体的不稳定性也会导致 NO 的不可控释放。

虽然目前报道了很多 NO供体, 但是只有少量 的 NO 供体能够与运输载体组装成有效释放 NO 的 传递平台, 并且在生物医学上发挥作用。一方面 是因为大多数 $\mathrm{NO}$ 供体在生理条件下不稳定, 另一 方面是由于 $\mathrm{NO}$ 供体与现存的药物载体结合后丧失 了控制释放 NO 的功能。因此, 在开发新的 NO 运 输平台时, 要充分考虑到 $\mathrm{NO}$ 气体和 $\mathrm{NO}$ 供体的独 特的物理化学性质。总的来说, 将 $\mathrm{NO}$ 供体与药物 载体组装后, 可以延长 $\mathrm{NO}$ 供体释放 $\mathrm{NO}$ 的半衰期 并且更加方便地将 NO 运输到特定的组织和生物体 中。因此, 设计合理的多功能的 $\mathrm{NO}$ 传递平台对于 $\mathrm{NO}$ 在生物医学上的应用是非常有必要的。 


\section{References}

(1) Ignarro, L. J. Nitric Oxide: Biology and Pathobiology; Academic Press: San Diego, CA, 2000.

(2) Butler, A. R.; Nicholson, R. Life, Death and Nitric Oxide; Royal Society of Chemistry: Cambridge, 2003.

(3) Mann, B. E.; Motterlinib, R. Chem. Commun. 2007, 4197. doi: 10.1039/B704873D

(4) Fajardo, A. M.; Piazza, G. A.; Tinsley, H. N. Cancers 2014, 6, 436. doi: 10.3390/cancers6010436

(5) Garthwaite, J. Trends Neurosci. 1991, 14, 60. doi: 10.1016/ 0166-2236(93)90109-Y

(6) Xiang, H. J.; Guo, M.; Liu, J. G. Eur. J. Inorg. Chem. 2017, 1586. doi: 10.1002/ejic.201601135

(7) Feil, R.; Harper, K. B. EMBO Rep. 2006, 7, 149. doi: 10.1038/ sj.embor.7400627

(8) Friebe, A.; Koesling, D. Circ. Res. 2003, 93, 96. doi: 10.1161/ 01.RES.0000082524.34487.31

(9) Sehemy, A. E.; Postovita, L. M.; Fu, Y. X. Nitric Oxide 2016, 54, 30. doi: 10.1016/j.niox.2016.02.002

(10) Wang, P. G.; Xian, M.; Tang, X.; Wu, X.; Wen, Z.; Cai, T.; Janczuk, A. J. Chem. Rev. 2002, 102, 1091. doi: 10.1021/ cr0000401

(11) Ostrowski, A. D.; Ford, P. C. Dalton Trans. 2009, 10660 doi: $10.1039 / \mathrm{B} 912898 \mathrm{~K}$

(12) Ford, P. C. Nitric Oxide 2013, 34, 56. doi: 10.1016/j. niox.2013.02.001

(13) Ford, P. C. Acc. Chem. Res. 2008, 41, 190. doi: 10.1021/ ar700128y

(14) Fry, N. L.; Wei, J.; Mascharak, P. K. Inorg. Chem. 2011, 50, 9045. doi: 10.1021/ic201242d

(15) Fry, N. L.; Mascharak, P. K. Acc. Chem. Res. 2011, 44, 289. doi: $10.1021 / \operatorname{ar} 100155 t$

(16) Rose, M. J.; Mascharak, P. K. Coord. Chem. Rev. 2008, 252, 2093. doi: 10.1016/j.ccr.2007.11.011

(17) Rose, M. J.; Mascharak, P. K. Curr. Opin. Chem. Biol. 2008, 12, 238. doi: 10.1016/j.cbpa.2008.02.009

(18) Sortino, S. Chem. Soc. Rev. 2010, 39, 2903. doi: 10.1039/ B908663N

(19) Sortino, S. J. Mater. Chem. 2012, 22, 301. doi: 10.1039/ C1JM13288A

(20) Kim, J.; Saravanakumar, G.; Choi, H. W.; Park, D.; Kim, W. J. J. Mater. Chem. B 2014, 2, 341. doi: 10.1039/C3TB21259A

(21) Nichols, S. P.; Storm, W. L.; Koh, A.; Schoenfisch, M. H. Adv. Drug Deliv. Rev. 2012, 64, 1177. doi: 10.1016/j. addr.2012.03.002

(22) Naghavi, N.; de Mel, A.; Alavijeh, O. S.; Cousins, B. G.; Seifalian, A. M. Small 2013, 9, 22. doi: 10.1002/ smll.201200458

(23) Jen, M. C.; Serrano, M. C.; van Lith, R.; Ameer, G. A. Adv. Funct. Mater. 2012, 22, 239. doi: 10.1002/adfm.201101707

(24) Kim, J.; Lee, Y.; Singha, K.; Kim, H. W.; Shin, J. H.; Jo, S.;
Han, D. K.; Kim, W. J. Bioconjugate Chem. 2011, 22, 1031. doi: 10.1021/bc100405c

(25) Reynolds, M. M.; Frost, M. C.; Meyerhoff, M. E. Free Radical Biol. Med. 2004, 37, 926. doi: 10.1016/j. freeradbiomed.2004.06.019

(26) Friedman, A.; Friedman, J. Expert Opin. Drug Delivery 2009, 6, 1113. doi: 10.1517/17425240903196743

(27) Barraud, N.; Kardak, B. G.; Yepuri, N. R.; Howlin, R. P.; Webb, J. S.; Faust, S. N.; Kjelleberg, S.; Rice, S. A.; Kelso, M. J. Angew. Chem. Int. Ed. 2012, 51, 9057. doi: 10.1002/ anie. 201202414

(28) Sharma, K.; Iyer, A.; Sengupta, K.; Chakrapani, H. Org. Lett. 2013, 15, 2636. doi: 10.1021/o1400884v

(29) Dharmaraja, A. T.; Ravikumar, G.; Chakrapani, H. Org. Lett. 2014, 16, 2610. doi: 10.1021/o15010643

(30) Gao, J.; Zheng, W.; Zhang, J.; Guan, D.; Yang, Z.; Kongab, D.; Zhao, Q. Chem. Commun. 2013, 49, 9173. doi: 10.1039/ $\mathrm{C} 3 \mathrm{CC} 45666 \mathrm{H}$

(31) Riccio, D. A.; Schoenfisch, M. H. Chem. Soc. Rev. 2012, 41, 3731. doi: $10.1039 / \mathrm{C} 2 \mathrm{CS} 15272 \mathrm{~J}$

(32) Ratanatawanate, C.; Chyao, A.; Balkus, K. J., Jr. J. Am. Chem. Soc. 2011, 133, 3492. doi: 10.1021/ja109328a

(33) Harding, J. L.; Reynolds, M. M. J. Am. Chem. Soc. 2012, 134, 3330. doi: $10.1021 / \mathrm{ja} 210771 \mathrm{~m}$

(34) Tan, L.; Wan, A.; Li, H. ACS Appl. Mater. Interfaces 2013, 5, 11163. doi: $10.1021 / \mathrm{am} 4034153$

(35) Fukuhara, K.; Kurihara, M.; Miyata, N. J. Am. Chem. Soc. 2001, 123, 8662. doi: 10.1021/ja0109038

(36) Suzuki, T.; Nagae, O.; Kato, Y.; Nakagawa, H.; Fukuhara, K.; Miyata, N. J. Am. Chem. Soc. 2005, 127, 11720. doi: 10.1021/ ja0512024

(37) Hishikawa, K.; Nakagawa, H.; Furuta, T.; Fukuhara, K.; Tsumoto, H.; Suzuki, T.; Miyata, N. J. Am. Chem. Soc. 2009, 131, 7488. doi: 10.1021/ja8093668

(38) Ieda, N.; Nakagawa, H.; Peng, T.; Yang, D.; Suzuki, T.; Miyata, N. J. Am. Chem. Soc. 2012, 134, 2563. doi: 10.1021/ ja206744z

(39) Ieda, N.; Hotta, Y.; Miyata, N.; Kimura, K.; Nakagawa, H. J. Am. Chem. Soc. 2014, 136, 7085. doi: 10.1021/ja5020053

(40) Kitamura, K.; Kawaguchi, M.; Ieda, N.; Miyata, N.; Nakagawa, H. ACS Chem. Biol. 2016, 11, 1271. doi: 10.1021/ acschembio.5b00962

(41) Rose, M. J.; Fry, N. L.; Marlow, R.; Hinck, L.; Mascharak, P. K. J. Am. Chem. Soc. 2008, 130, 8834. doi: 10.1021/ja801823f

(42) Fry, N. L.; Heilman, B. J.; Mascharak, P. K. Inorg. Chem. 2011, 50, 317. doi: 10.1021/ic1019873

(43) Xiang, H. J.; An, L.; Tang, W. W.; Yang, S. P.; Liu, J. G. Chem. Commun. 2015, 51, 2555. doi: 10.1039/C4CC09869B

(44) Xiang, H. J.; Deng, Q.; An, L.; Guo, M.; Yang, S. P.; Liu, J. G. Chem. Commun. 2016, 52, 148. doi: 10.1039/C5CC07006F

(45) Xiang, H. J.; Guo, M.; An, L.; Yang, S. P.; Zhang, Q. L.; Liu, J. 
G. J. Mater. Chem. B 2016, 4, 4667. doi: 10.1039/ C6TB00730A

(46) Goyan, R. L.; Cramb, D. T. Photochem. Photobiol. 2000, 72, 821. doi: 10.1562/0031-8655(2000)0720821NITPEO2.0.CO2

(47) Wecksler, S.; Mikhailovsky, A.; Ford, P. C. J. Am. Chem. Soc. 2004, 126, 13566. doi: 10.1021/ja045710+

(48) Conrado, C. L.; Wecksler, S.; Egler, C.; Magde, D.; Ford, P. C. Inorg. Chem. 2004, 43, 5543. doi: 10.1021/ic049459a

(49) Wecksler, S. R.; Mikhailovsky, A.; Korystov, D.; Ford, P. C. J. Am. Chem. Soc. 2006, 128, 3831. doi: 10.1021/ja057977u

(50) Saraiva, J.; M.-Oliveira, S. S.; Cicillini, S. A.; Eloy, J. O.; Marchetti, J. M. J. Drug Delivery 2011, 2011, 936438. doi: $10.1155 / 2011 / 936438$

(51) Sharma, A.; Sharma, U. S. Int. J. Pharm. 1997, 154, 123. doi: 10.1016/S0378-5173(97)00135-X

(52) Lian,T.; Ho, R. J. J. Pharm. Sci. 2001, 90, 667. doi: 10.1002/ jps. 1023

(53) Malam, Y.; Loizidou, M.; Seifalian, A. M. Trends Pharmacol. Sci. 2009, 30, 592. doi: 10.1016/j.tips.2009.08.004

(54) Tai, L. A.; Wang, Y. C.; Yang, C. S. Nitric Oxide 2010, 23, 60. doi: 10.1016/j.niox.2010.04.003

(55) Ostrowski, A. D.; Lin, B. F.; Tirrell, M. V.; Ford, P. C. Mol. Pharmaceutics 2012, 9, 2950. doi: 10.1021/mp300139y

(56) Suchyta, D. J.; Schoenfisch, M. H. Mol. Pharmaceutics 2015, 12, 3569. doi: 10.1021/acs.molpharmaceut.5b00248

(57) Nakanishi, K.; Koshiyama, T.; Iba, S.; Ohba, M. Dalton Trans. 2015, 44, 14200. doi: 10.1039/C5DT02352A

(58) Rahman, A.; Padavettan, V. J. Nanomater. 2012, 2012, 132424. doi: $10.1155 / 2012 / 132424$

(59) Roy, I.; Ohulchanskyy, T. Y.; Pudavar, H. E.; Bergey, E. J.; Oseroff, A. R.; Morgan, J.; Dougherty, T. J.; Prasad, P. N. J. Am. Chem. Soc. 2003, 125, 7860. doi: 10.1021/ja0343095

(60) Xu, Z. P.; Zeng, Q. H.; Lu, G. Q.; Yu, A. B. Chem. Eng. Sci. 2006, 61, 1027. doi: 10.1016/j.ces.2005.06.019

(61) Rim, H. P.; Min, K. H.; Lee, H. J.; Jeong, S. Y.; Lee, S. C. Angew. Chem. Int. Ed. 2011, 50, 8853. doi: 10.1002/ anie.201101536

(62) Bagwe, R. P.; Yang, C.; Hilliard, L. R.; Tan, W. Langmuir 2004, 20, 8336. doi: 10.1021/1a049137j

(63) Swihart, M. T. Curr. Opin. Colloid Interface Sci. 2003, 8, 127. doi: 10.1016/S1359-0294(03)00007-4

(64) Barbe, C.; Bartlett, J.; Kong, L. G.; Finnie, K.; Lin, H. Q.; Larkin, M.; Calleja, S.; Bush, A.; Calleja, G. Adv. Mater. 2004, 16, 1959. doi: 10.1002/adma.200400771

(65) Park, C.; Oh, K.; Lee, S. C.; Kim, C. Angew. Chem. Int. Ed. 2007, 46, 1455. doi: 10.1002/anie.200603404

(66) Zhang, H.; Annich, G. M.; Miskulin, J.; Stankiewicz, K.; Osterholzer, K.; Merz, S. I.; Bartlett, R. H.; Meyerhoff, M. E. J. Am. Chem. Soc. 2003, 125, 5015. doi: 10.1021/ja0291538

(67) Carpenter, A. W.; Slomberg, D. L.; Rao, K. S.; Schoenfisch, M. H. ACS Nano, 2011, 5, 7235. doi: 10.1021/nn202054f
(68) Shin, J. H.; Metzger, S. K.; Schoenfisch, M. H. J. Am. Chem. Soc. 2007, 129, 4612. doi: 10.1021/ja0674338

(69) Carpenter, A. W.; Worley, B. V.; Slomberg, D. L.; Schoenfisch, M. H. Biomacromolecules 2012, 13, 3334. doi: 10.1021/ bm301108x

(70) Rahmat, N.; Abdullah, A. Z.; Mohamed, A. R. A. J. Appl. Sci. 2010, 7, 1579. doi: 10.3844/ajassp.2010.1579.1586

(71) Li, Z.; Barnes, J. C.; Bosoy, A.; Stoddart, J. F.; Zink, J. I. Chem. Soc. Rev. 2012, 41, 2590. doi: 10.1039/C1CS15246G

(72) Lu, Y.; Slomberg, D. L.; Sun, B.; Schoenfisch, M. H. Small 2013, 9, 2189. doi: 10.1002/smll.201201798

(73) Carpenter, A. W.; Reighard, K. P.; Saavedra, J. E.; Schoenfisch, M. H. Biomater. Sci. 2013, 1, 456. doi: 10.1039/C3BM00153A

(74) Choi, H. W.; Kim, J.; Kim, J.; Kim, Y.; Song, H. B.; Kim, J. H.; Kim, K.; Kim, W. J. ACS Nano 2016, 10, 4199. doi: 10.1021/acsnano.5b07483

(75) Heilman, B. J.; St John, J.; Oliver, S. R.; Mascharak, P. K. J. Am. Chem. Soc. 2012, 134, 11573. doi: 10.1021/ja3022736

(76) Frost, M. C.; Meyerhoff, M. E. J. Biomed. Mater. Res., Part A 2005, 72, 409. doi: 10.1002/jbm.a.30275

(77) Riccio, D. A.; Nugent, J. L.; Schoenfisch, M. H. Chem. Mater. 2011, 23, 1727. doi: 10.1021/cm102510q

(78) Nam, J.; Won, N.; Bang, J.; Jin, H.; Park, J.; Jung, S.; Park, Y.; Kim, S. Adv. Drug Delivery Rev. 2013, 65, 622. doi: 10.1016/j. addr.2012.08.015

(79) Wang, L. S.; Chuang, M. C.; Ho, J. A. Int. J. Nanomed. 2012, 7, 4679. doi: 10.2147/IJN.S33065

(80) Pinaud, F.; Michalet, X.; Bentolila, L. A.; Tsay, J. M.; Doose, S.; Li, J. J.; Iyer, G.; Weiss, S. Biomaterials 2006, 27, 1679. doi: 10.1016/j.biomaterials.2005.11.018

(81) Zrazhevskiy, P.; Sena, M.; Gao, X. Chem. Soc. Rev. 2010, 39, 4326. doi: 10.1039/B915139G

(82) Bera, D.; Qian, L.; Tseng, T. K.; Holloway, P. H. Materials 2010, 3, 2260. doi: 10.3390/ma3042260

(83) Neuman, D.; Ostrowski, A. D.; Absalonson, R. O.; Strouse, G. F.; Ford, P. C. J. Am. Chem. Soc. 2007, 129, 4146. doi: 10.1021/ ja070490w

(84) Neuman, D., Ostrowski, A. D.; Mikhailovsky, A. A.; Absalonson, R. O.; Strouse, G. F.; Ford, P. C. J. Am. Chem. Soc. 2008, 130, 168. doi: 10.1021/ja074164s

(85) Burks, P. T.; Ostrowski, A. D.; Mikhailovsky, A. A.; Chan, E. M.; Wagenknecht, P. S.; Ford, P. C. J. Am. Chem. Soc. 2012, 134, 13266. doi: 10.1021/ja300771w

(86) Tan, L.; Wan, A.; Zhu, X.; Li, H. Chem. Commun. 2014, 50, 5725. doi: $10.1039 / \mathrm{C} 4 \mathrm{CC} 01126 \mathrm{~K}$

(87) Zhao, L.; Peng, J.; Huang, Q.; Li, C.; Chen, M.; Sun, Y.; Lin, Q.; Zhu, L.; Li, F. Adv. Funct. Mater. 2014, 24, 363. doi: 10.1002/adfm.201302133

(88) Gu, Z.; Yan, L.; Tian, G.; Li, S.; Chai, Z.; Zhao, Y. Adv. Mater. 2013, 25, 3758. doi: 10.1002/adma.201301197

(89) Garcia, J. V.; Yang, J.; Shen, D.; Yao, C.; Li, X.; Wang, R.; 
Stucky, G. D.; Zhao, D.; Ford, P. C.; Zhang, F. Small 2012, 8, 3800. doi: 10.1002/smll.201201213

(90) Burks, P. T.; Garcia, J. V.; GonzalezIrias, R.; Tillman, J. T.; Niu, M.; Mikhailovsky, A. A.; Zhang, J.; Zhang, F.; Ford, P. C. J. Am. Chem. Soc. 2013, 135, 18145. doi: 10.1021/ja408516w

(91) Dong, K.; Ju, E.; Gao, N.; Wang, Z.; Ren, J.; Qu, X. Chem. Commun. 2016, 52, 5312. doi: 10.1039/C6CC00774K

(92) Fan, W.; Bu, W.; Zhang, Z.; Shen, B.; Zhang, H.; He, Q.; Ni, D.; Cui, Z.; Zhao, K.; Bu, J.; Du, J.; Liu, J.; Shi, J. Angew. Chem. Int. Ed. 2015, 127, 14026. doi: 10.1002/anie.201504536

(93) Zhang, X.; Tian, G.; Yin, W.; Wang, L.; Zheng, X.; Yan, L.; Li, J.; Su, H.; Chen, C.; Gu, Z.; Zhao, Y. Adv. Funct. Mater. 2015, 25, 3049. doi: 10.1002/adfm.201404402

(94) Pang, C. L.; Lindsay, R.; Thornton, G. Chem. Soc. Rev. 2008, 37, 2328. doi: 10.1039/B719085A

(95) Dohnalek, Z.; Lyubinetsky, I.; Rousseau, R. Prog. Surf. Sci. 2010, 85, 161. doi: 10.1016/j.progsurf.2010.03.001

(96) Feng, X.; Zhu, K.; Frank, A. J.; Grimes, C. A.; Mallouk, T. E. Angew. Chem. Int. Ed. 2012, 51, 2727. doi: 10.1002/ anie. 201108076

(97) Yin, Z. F.; Wu, L.; Yang, H. G.; Su, Y. H. Phys. Chem. Chem. Phys. 2013, 15, 4844. doi: 10.1039/C3CP43938K

(98) Huang, P.; Lin, J.; Wang, X.; Wang, Z.; Zhang, C.; He, M.; Wang, K.; Chen, F.; Li, Z.; Shen, G.; Cui, D.; Chen, X. Adv. Mater. 2012, 24, 5104. doi: 10.1002/adma.201200650

(99) Wang, X.; Cao, L.; Yang, S. T.; Lu, F.; Meziani, M. J.; Tian, L.;
Sun, K. W.; Bloodgood, M. A.; Sun, Y. P. Angew. Chem. Int. Ed. 2010, 49, 5310. doi: 10.1002/anie.201000982

(100) Yang, X. D.; Xiang, H. J.; An, L.; Yang, S. P.; Liu, J. G. New J. Chem. 2015, 39, 800. doi: 10.1039/C4NJ01758G

(101) Xu, J.; Zeng, F.; Wu, H.; Hu, C.; Yu, C.; Wu, S. Small 2014, 10, 3750. doi: 10.1002/sml1.201400437

(102) Fowley, C.; McHale, A. P.; McCaughan, B.; Fraix, A.; Sortino, S.; Callan, J. F. Chem. Commun. 2015, 51, 81. doi: 10.1039/ $\mathrm{C} 4 \mathrm{CC} 07827 \mathrm{~F}$

(103) Deng, Q.; Xiang, H. J.; Tang, W. W.; An, L.; Yang, S. P.; Zhang, Q. L.; Liu, J. G. J. Inorg. Biochem. 2016, 165, 152. doi: 10.1016/j.jinorgbio.2016.06.011

(104) Zhang, H.; Gruner, G.; Zhao, Y. J. Mater. Chem. B 2013, l, 2542. doi: 10.1039/C3TB20405G

(105) Mao, H. Y.; Laurent, S.; Chen, W.; Akhavan, O.; Imani, M.; Ashkarran, A.; Mahmoudi, M. Chem. Rev. 2013, 113, 3407. doi: $10.1021 / \mathrm{cr} 300335 \mathrm{p}$

(106) Liu, J.; Cui, L.; Losic, D. Acta Biomater. 2013, 9, 9243. doi: 10.1016/j.actbio.2013.08.016

(107) Fan, J.; He, N.; He, Q.; Liu, Y.; Ma, Y.; Fu, X.; Liu, Y.; Huang, P.; Chen, X. Nanoscale 2015, 7, 20055. doi: 10.1039/ C5NR06630A

(108) Marino, N.; Petralia, S.; Lloret, M. P.; Mosinger, J.; Conoci, S.; Sortino, S. J. Mater. Chem. B 2016, 4, 5825. doi: 10.1039/ C6TB01599A 